\title{
Enterobactérias associadas a adultos de Musca domestica (Linnaeus, 1758) (Diptera: Muscidae) e Chrysomya megacephala (Fabricius, 1754) (Diptera: Calliphoridae) no Jardim Zoológico, Rio de Janeiro
}

[Enterobacteria associated to adults of Musca domestica (Linnaeus, 1758) (Diptera: Muscidae) and Chrysomya megacephala (Fabricius, 1754) (Diptera: Calliphoridae) at the Zoo of Rio de Janeiro, Brazil]

\author{
V.C. Oliveira', J.M. D'Almeida', I.V. Abalem de Sá $^{1}$, J.R. Mandarino ${ }^{2}$, C.A. Solari ${ }^{2}$ \\ ${ }^{1}$ Instituto Oswaldo Cruz \\ Avenida Brasil, 4365 \\ 21045-900 - Rio de Janeiro, RJ \\ ${ }^{2}$ Hospital Universitário Gaffrée e Guinle - UNIRIO - Rio de Janeiro, RJ
}

\begin{abstract}
RESUMO
Enterobactérias foram identificadas em adultos de Musca domestica (Linnaeus, 1758) (Diptera: Muscidae) e Chrysomya megacephala (Fabricius, 1754) (Diptera: Calliphoridae). Ambas as espécies foram capturadas no Jardim Zoológico da cidade do Rio de Janeiro e tiveram a superfície externa do corpo lavada e o sistema digestivo dissecado, para análise bacteriológica. Identificaram-se Escherichia coli, Citrobacter sp., Proteus mirabilis, Morganella sp., Klebsiella sp., Pseudomonas sp., Enterobacter sp. e Salmonella Agona. P. mirabilis foi o isolado bacteriano mais freqüente. Em duas amostragens (8\%) de C. megacephala, isolou-se Salmonella Agona. As amostras de E. coli não foram enteropatogênicas. $M$. domestica e C. megacephala são potenciais veiculadoras de bactérias causadoras de enterites em humanos e animais.
\end{abstract}

Palavras-chave: Musca domestica, Chrysomya megacephala, dípteros muscóides, enterobactérias, jardim zoológico

\section{ABSTRACT}

Enterobacteria were identified in adults of Musca domestica (Linnaeus, 1758) (Diptera: Muscidae) and Chrysomya megacephala (Fabricius, 1754) (Diptera: Calliphoridae). Both species were captured in the Zoo of Rio de Janeiro. They had their external body surface washed and their digestive system dissected for bacteriological analysis. Escherichia coli, Citrobacter $s p$., Proteus mirabilis, Morganella $s p$., Klebsiella $s p$., Pseudomonas $s p$., Enterobacter $s p$. and Salmonella serovar Agona were isolated in the samples. P. mirabilis was the species most frequent isolated. Strains of Salmonella Agona were isolated from two samples (8\%) of C. megacephala. Enteropathogenic E. coli was not isolated. M. domestica and C. megacephala showed themselves as potential vectors of agents related to enteric diseases in humans and other animals.

Keywords: Musca domestica, Chrysomya megacephala, muscoids diptera, enterobacteria, Zoo

Recebido em 23 de abril de 2004

Aceito em 3 de janeiro de 2006

E-mail: vcris@ioc.fiocruz.br 


\section{INTRODUÇÃO}

Os dípteros muscóides são considerados de grande importância pela sua capacidade de utilizar diferentes substratos para alimentação e desenvolvimento de suas larvas (d'Almeida e Almeida, 1998). De acordo com a natureza dos criadouros, as moscas adultas podem ter maior ou menor importância na veiculação de microrganismos patogênicos. Nuorteva (1959), Imbiriba et al. (1979), Furlanetto et al. (1984), Fischer et al. (2001) verificaram a presença de bactérias enteropatogênicas em dípteros muscóides.

Bactérias têm sido identificadas no trato digestivo de várias espécies de insetos, constituindo a microbiota intestinal (Tanada e Kaya, 1993). Em algumas espécies, as bactérias podem até mesmo interferir no desenvolvimento de parasitos (ex.: Plasmodium em Anopheles) que são transmitidos por esses insetos (Pumpuni et al., 1996). É importante ressaltar a necessidade da microbiota intestinal no processo digestivo dos insetos (Waterhouse, 1957), embora determinadas bactérias do trato digestivo possam tornar-se patogênicas e acarretar alto índice de mortalidade em colônia de Lutzomyia longipalpis (Diptera: Psychodidae) (Figueiredo et al., 1997).

O jardim zoológico do Rio de Janeiro foi considerado excelente ecossistema para a proliferação de moscas, devido à grande quantidade de fezes e restos de alimentos de origem vegetal e animal, os quais podem estar contaminados com vários patógenos (d'Almeida 1989; Oliveira et al., 1999, 2002). Em estudos realizados por Oliveira et al. (1999; 2002), as espécies Musca domestica (Linnaeus, 1758) (Diptera: Muscidae) e Chrysomya megacephala (Fabricius, 1754) (Diptera: Calliphoridae) foram os muscóides mais abundantes no jardim zoológico da cidade do Rio de Janeiro.

O objetivo deste estudo foi identificar enterobactérias, associadas a Musca domestica e Chrysomya megacephala, capturadas no jardim zoológico do Rio de Janeiro, RJ.

\section{MATERIAL E MÉTODOS}

Adultos de $M$. domestica e $C$. megacephala foram capturados no jardim zoológico da cidade do Rio de Janeiro, com o auxílio de rede entomológica, no período de setembro a dezembro de 1997. As moscas capturadas foram transferidas para tubos de ensaio estéreis e levadas ao laboratório. Para as análises bacteriológicas, foram examinados 20 exemplares de cada espécie/tubo de ensaio, perfazendo um total de 20 lotes de $M$. domestica e 25 lotes de C. megacephala, analisados com 400 e 500 exemplares de $M$. domestica e $C$. megacephala, respectivamente.

Para a obtenção do inóculo da superfície do corpo, acrescentaram-se, a cada tubo, $5 \mathrm{ml}$ de solução salina estéril que, após agitação, foram transferidos para recipientes de vidro estéreis e, em seguida, semeados em meio para crescimento de bactérias. Após a passagem em salina, as moscas foram lavadas duas vezes em hipoclorito de sódio a 5\% e em água destilada estéril, para posterior dissecação do sistema digestivo. Os inóculos obtidos do corpo dos insetos e do conteúdo do intestino anterior, médio e posterior dos dípteros foram semeados em placas de ágar Hektoen (HK), ágar verde brilhante (VB), ágar eosina-azul de metileno (EMB) e em meios de enriquecimento seletivo para Salmonella caldo tetrationato de Kauffmann (1ml) e caldo Rappaport-Vassiliadis $(0,1 \mathrm{ml})$, que foram incubados a $37^{\circ} \mathrm{C}$ por $18-24 \mathrm{~h}$.

Após a incubação, as colônias que apresentaram características de enterobactérias foram semeadas em tubos de ágar Costa-Vernin (CV), mantidas a $37^{\circ} \mathrm{C}$ durante $18-24 \mathrm{~h}$. Após esse período, as colônias que apresentaram reações típicas para $E$. coli foram identificadas bioquimicamente. As cepas caracterizadas como E. coli foram semeadas em ágar simples e mantidas a $37^{\circ} \mathrm{C}$ por $18-24 \mathrm{~h}$. Em seguida, foi preparada uma suspensão espessa, em salina a $0,85 \%$, a qual foi submetida à prova de soroaglutinação, em lâminas para antígenos do grupo OB, utilizando-se anti-soros polivalentes ${ }^{1}$ anti $E$. coli ( $E$. coli enteropatogênica clássica polivalentes A, B e C; enteroinvasora polivalentes A e B e enterohemorrágica $\mathrm{O}: 157)$.

Para verificar a presença de Shigella e Salmonella, das placas de $\mathrm{HK}$ e VB, foram isoladas colônias de bactérias não fermentadoras de lactose, as quais eram semeadas em tubos de

${ }^{1}$ PROBAC - São Paulo, Brasil 
$\mathrm{CV}$ e incubadas a $37^{\circ} \mathrm{C}$ durante $18-24 \mathrm{~h}$. Depois, as culturas foram submetidas a testes bioquímicos e sorológicos.

Para colônias típicas e suspeitas de Salmonella, foram realizadas provas de produção de desaminase da fenilalanina, descarboxilase da lisina, urease, fermentação de dulcitol, utilização do malonato, produção de indol, de $\mathrm{H}_{2} \mathrm{~S}$, de Voges Proskauer e de vermelho de metila, utilização de citrato e motilidade. As cepas com características de Salmonella foram submetidas à prova de soro-aglutinação, em lâminas, para antígeno somático $\mathrm{O}$ e flagelares $\mathrm{H}^{2}$. Para as colônias sugestivas de Shigella, foram feitas análises de fermentação de glicose, descarboxilação da ornitina, produção de urease e indol, utilização do citrato e motilidade, além da prova de soro-aglutinação, em lâmina, para antígeno somático, utilizando anti-soros específicos polivalentes ${ }^{2}$.

Foram seguidas as recomendações preconizadas para caracterização bioquímica, segundo Costa e Hofer (1974), Ewing (1986) e Mac-Fadin (1993) e antigênica segundo Costa e Hofer (1974), Ewing (1986) e Popoff e Le Minor (1997).

\section{RESULTADOS E DISCUSSÃO}

Os resultados mostram que Proteus mirabilis foi a espécie mais freqüente em $C$. megacephala tanto na superfície do corpo quanto no conteúdo intestinal (Tab. 1). Nos lotes de M. domestica houve freqüência elevada de Citrobacter sp. na superfície do corpo e de Proteus mirabilis no conteúdo intestinal. A maioria das bactérias do gênero Proteus está associada a processos de putrefação, sendo encontradas não só em fezes de mamíferos (normais ou diarréicas) e águas de esgoto, como também em carnes em decomposição e feridas (Bier, 1975).

M. domestica e C. megacephala estão associadas à matéria orgânica em decomposição. Entretanto, a microbiota observada nesses muscóides não diferiu muito daquela encontrada em alguns dípteros hematófagos e nas moscas das frutas (Diptera: Tephritidae). Oliveira et al. (2000) isolaram do trato digestivo de fêmeas do díptero Lutzomyia longipalpis (Diptera: Psychodidae) as

${ }^{2}$ Sanofi-Pasteur, França bactérias: Acinetobacter lwoffii, Stenotrophomonas maltophilia, Pseudomonas putid, Flavimonas orizihabitans, Enterobacter cloacae e Klebsiella ozaenae. Kuzima et al. (2001) isolaram do trato digestivo de Anastrepha ludens (Diptera: Tephritidae): Listeria, Enterobacter, Providencia, Serratia, Staphylococcus, Citrobacter, Streptococcus, Bacillus cereus, Pseudomonas aeruginosa, Aeromonas hydrophila e Klebsiella pneumoniae. Nos exemplos citados, tanto L. longipalpis quanto $A$. ludens apresentaram fauna bacteriológica variada e composta, inclusive, por bactérias patogênicas para o homem e para os animais.

Morganella sp., Klebesiella sp., Pseudomanas sp. e Enterobacter sp. também foram freqüentes na superfície do corpo e no conteúdo do intestino de C. megacephala e M. domestica (Tab. 1). O gênero Enterobacter tem sido relatado por diversos autores, como sendo o mais freqüente no intestino de insetos (Tanada e Kaya, 1993), inclusive naqueles de importância médica (Dillon et al., 1996).

Dos 25 lotes analisados de C. megacephala, observou-se a presença de Salmonella Agona em apenas dois lotes $(8 \%)$ provenientes do lavado da superfície do corpo e um lote $(4 \%)$ do conteúdo intestinal. Furlanetto et al. (1984), ao trabalharem com espécimes de $C$. megacephala capturados em bancas de pescados de feiras livres de São Paulo, não obtiveram resultado positivo para Salmonella. C. megacephala, conhecida como mosca-das-latrinas, é considerada como boa colonizadora, ocupando vários habitats, desde carcaças de animais, fezes de galinha, depósitos de lixo a aterros sanitários. Além disso, possui grande capacidade de dispersão, o que aumenta o seu potencial de disseminação de patógenos (Guimarães et al., 1979).

Nos lotes provenientes da superfície do corpo e do intestino de $M$. domestica não foram encontradas cepas de Salmonella. Vários autores, incriminam $M$. domestica como transmissora de Salmonella enteritidis e typhimurium, Shigella sp., Vibrio sp. e Staphylococcus sp. (Khin et al., 1989; Levine e Levine 1991; Fotedar et al., 1992). De acordo com Greenberg e Klowden (1972), M. domestica é considerada cosmopolita, eusinantrópica e endófila. 
Tabela 1. Freqüência das bactérias isoladas da superfície do corpo e do intestino de Chrysomya megacephala e Musca domestica, capturadas no jardim zoológico da cidade do Rio de Janeiro, no período de setembro de 1997 a dezembro de 1997

\begin{tabular}{|c|c|c|c|c|c|c|c|c|}
\hline \multirow[b]{3}{*}{ Bactéria } & \multicolumn{8}{|c|}{ Lotes positivos } \\
\hline & \multirow{2}{*}{\multicolumn{2}{|c|}{$\begin{array}{c}\text { C. megacephala } \\
\text { (superfície do corpo) } \\
\text { N Freqüência }\end{array}$}} & \multirow{2}{*}{\multicolumn{2}{|c|}{$\begin{array}{l}\text { C. megacephala } \\
\text { (intestinos) } \\
\text { N Freqüência }\end{array}$}} & \multicolumn{2}{|c|}{$\begin{array}{c}\text { M. domestica } \\
\text { (superfície do corpo) }\end{array}$} & \multicolumn{2}{|c|}{$\begin{array}{l}\text { M. domestica } \\
\text { (intestinos) }\end{array}$} \\
\hline & & & & & $\mathrm{N}$ & Freqüência & $\mathrm{N}$ & Freqüência \\
\hline Escherichia coli & 3 & $12 \%$ & 8 & $32 \%$ & 1 & $5 \%$ & 2 & $10 \%$ \\
\hline Citrobacter sp. & 11 & $44 \%$ & 10 & $40 \%$ & 12 & $60 \%$ & 11 & $55 \%$ \\
\hline Proteus mirabilis & 15 & $60 \%$ & 16 & $64 \%$ & 11 & $55 \%$ & 14 & $70 \%$ \\
\hline Morganella sp. & 9 & $36 \%$ & 7 & $28 \%$ & 8 & $40 \%$ & 5 & $25 \%$ \\
\hline Klebesiella sp. & 9 & $36 \%$ & 6 & $24 \%$ & 7 & $35 \%$ & 7 & $35 \%$ \\
\hline Pseudomonas sp. & 10 & $40 \%$ & 10 & $40 \%$ & 8 & $40 \%$ & 11 & $55 \%$ \\
\hline Enterobacter sp. & 2 & $8 \%$ & 3 & $12 \%$ & 1 & $5 \%$ & 2 & $10 \%$ \\
\hline Salmonella Agona & 2 & $8 \%$ & 3 & $4 \%$ & & 0 & & 0 \\
\hline
\end{tabular}

P. mirabilis foi isolado em quase todos os lotes pesquisados, e tal fato pode explicar a baixa freqüência de Salmonella. Greenberg et al. (1970) relataram que alguns fatores podem afetar a proliferação de Salmonella em moscas adultas, como a existência de flora mista e o antagonismo entre espécies. Greenberg e Klowden (1972) demostraram a redução e até mesmo a extinção de Salmonella pelo gênero Proteus.

A pesquisa de $E$. coli, em conteúdo do intestino, foi positiva para oito lotes analisados $(32 \%)$ de C. megacepala, e em apenas dois (10\%) de $M$. domestica, porém não foi encontrado $E$. coli enteropatogênica. Brygoo et al. (1962) isolaram e identificaram E. coli enteropatogênica em Chrysomya chloropyga (Diptera: Calliphoridae) capturadas na cidade de Tananarive, em Madagascar.

A transmissão de patógenos por moscas através de suas fezes, regurgitação e pelo contato de seu corpo é um importante meio de disseminação de patógenos para o alimento do homem. Lindsay e Scudder (1956) relataram que a presença e a quantidade de moscas em um local podem ser utilizadas como indicadores de condições sanitárias. Shimizu et al. (1965) ressaltaram que a veiculação de patógenos por moscas é dependente das más condições sanitárias. Putman (1983) relatou que fezes frescas, além de atrair elevado número de espécies de dípteros, são consideradas um meio em que $o$ desenvolvimento larval pode completar-se mais rapidamente. Assim, o acúmulo de fezes observado freqüentemente nos abrigos dos animais do zoológico assume importante papel epidemiológico.
Os resultados do presente trabalho demonstram o risco em potencial dos dípteros muscóides na veiculação de agentes etiológicos causadores de doenças entéricas não só para os animais cativos, como também para a população humana. Maldonado e Centeno (2003), ao proporem o danger-index, que é uma modificação do índice proposto por Mihályi (1967), constataram que $M$. domestica apresentou baixo índice e $C$. megacephala, elevado. Esse resultado aponta para o risco sanitário em potencial que a espécie C. megacephala pode representar.

Quanto à microbiota do trato digestivo desses muscóides, torna-se necessário estudá-la mais detidamente, procurando isolar as bactérias de moscas criadas em laboratório para, assim, avaliar a influência dessa microbiota sobre os processos metabólicos das moscas.

\section{AGRADECIMENTOS}

À direção da Fundação RIO-ZOO.

\section{REFERÊNCIAS BIBLIOGRÁFICAS}

BIER, O. Bacteriologia e Imunologia. 16.ed. São Paulo: Melhoramentos. Universidade de São Paulo, 1975. 516p.

BRYGOO, E.R.; SUREAU, P.; LeNOC, P. Virus et germes fecaux des mouches de I'agglomeration urbaine de Tananarive. Bull. Soc. Pathol. Exot., v.55, p.866-881, 1962

COSTA, C.A.; HOFER, E. Isolamento $e$ identificação de enterobacteriáceas. Monografia 
Instituto Oswaldo Cruz, Rio de Janeiro, Rio de Janeiro, 1974.

d' ALMEIDA, J.; ALMEIDA, J.R. Nichos tróficos em dípteros caliptrados, no Rio de Janeiro, RJ. Rev. Brasil. Biol., v.58, p.563-570, 1998

d'ALMEIDA, J.M. Substratos utilizados para a criação de dípteros caliptratos em área urbana do Município do Rio de Janeiro. Mem. Inst. Oswaldo Cruz, v.83, p.201-206, 1989.

DILLON, R.J.; EL KORDY, E.; LANEE, R.P. The prevalence of a microbiota in the digestive tract of Phlebotomus papatasi. Ann. Trop. Med. Parasitol., v.90, p.669-673, 1996.

EWING, W.H. Identification of Enterobacteriaceae. 2.ed. Minneapolis: Burgess Publishing, 1986. 187p.

FIGUEIREDO, A.R.; OLIVEIRA, S.M.P.; GORDANO-DIAS, C.M. et al. Presença de Serratia marcescens e Pseudomonas aeruginosa em colônias de flebotomíneos (Diptera: Psychodidae). In: CONGRESSO BRASILEIRO DE ENTOMOLOGIA, 16; ENCONTRO NACIONAL DE FITOSSANITARISTAS, 7.; CONGRESSO BRASILEIRO DE ENTOMOLOGIA, 1997. Anais... Salvador, 1997, p.260.

FISCHER, O.; MÁTLOVÁ, L.; DVORSKÁ, P. et al. Diptera as vectors of mycobacterial infections in cattle and pigs. Med. Vet. Entomol., v.15, p.208-211, 2001.

FOTEDAR, R.; BANERJEE, U.; SINGH, S. et al. The housefly (Musca domestica) as a carrier of pathogenic microorganisms in a hospital environment. J. Hosp. Infect., v.20, p. 209 -215, 1992.

FURLANETTO, S.M.P.; CAMPOS, M.L.C.; HÄRSI, C.M. et al. Microorganismos enteropatogênicos em moscas africanas pertencentes ao gênero Chrysomya (Diptera: Calliphoridae) no Brasil. Rev. Microbiol., v.15, p.170-174, 1984.

GREENBERG, B.; KLOWDEN, M.J. Enteric bacterial interaction in insects. Am. J. Clin. Nutr., v.25, p.1459-1466, 1972.

GREENBERG, B.; KOWALSKI, J.A.; KLOWDEN, M.J. Factors affecting the transmission of Salmonella by flies; natural resistance to colonization and bacterial interference. Inf. Immun., v.2, p.800-809, 1970.

GUIMARÃES, J.H.; PRADO, A.P.; BURALLI, G. M. Dispersal and distribution of three news introduced species of Chrysomya RobineauDesvoid in Brazil (Diptera, Calliphoridae). Rev. Bras. Entomol., v.23, p.245-255, 1979.

IMBIRIBA, A.S. Incidência de enterobactérias encontradas em lotes de moscas em abatedouros de Curitiba - Paraná e arredores. Arq. Biol. Tecnol., v.22, p.197-206, 1979.

KHIN, N.O.; SEBASTIAN, A.A.; AYE, T. Carriage of enteric bacterial pathogens by house flies in Yangon, Myanmar. J. Diarrh. Dis. Res., v.7, p. 81-84, 1989.

KUZIMA, L.V.; PELOQUIN, J.J.; VACEK, D.C. et al. Isolation and identification of bacteria associated with adult laboratory Mexican fruit flies, Anastrepha ludens (Diptera: Tephritidae). Curr. Microbiol., v.42, p. 290-294, 2001.

LEVINE, O. S.; LEVINE, M. M. Houseflies (Musca domestica) as mechanical vectors of shigellosis. Rev. Infect. Dis., v.13, p.688-696, 1991.

LINDSAY, D.R.; SCUDDER, H.I. Nonbiting flies and disease. Ann. Rev. Entomol, v.1, p.323346, 1956.

MAC-FADIN. Pruebas bioquímicas para la identificacion de bactérias de importância clínica. 2.ed. São Paulo: Panamericana, 1993.

MALDONADO, M.A.; CENTENO, N. Quantifying the potential pathogens transmission of the blowflies (Diptera: Calliphoridae). Mem. Inst. Oswaldo Cruz, v. 98, p.213-216, 2003.

MIHÁLYI, F. The danger-index of the synanthropic flies. Acta Zool. Hung., v.13, p.373-377, 1967.

NUORTEVA, P. Studies on the significance of flies in the transmission to the occurrence of poliomyelitis in Finland. Ann. Entomol. Fenn., v.25, p.1-24, 1959.

OLIVEIRA, S.M.P.; MORAES, B.A.; GONÇALVES, C.A. et al. Prevalência da microbiota no trato digestivo de Lutzomyia longipalpis (Lutz \& Neiva, 1912) (Diptera: Psychodidae) provenientes do campo. Rev. Soc. Bras. Med. Trop., v.33, p.319-322, 2000. 
OLIVEIRA, V.C.; d'ALMEIDA, J.M.; PAES, M.J.S. et al. Dinâmica populacional dos dípteros Calliphoridae na Fundação Rio-Zoo, Rio de Janeiro, RJ, Brasil. Entomol. Vect., v.6, p.264$276,1999$.

OLIVEIRA, V.C.; d'ALMEIDA, J.M.; PAES, M.J.S. et al. Population dynamics of Calyptrate Diptera (Muscidae and Sarcophagidae) at the Rio-Zoo Foudation, Rio de Janeiro, RJ, Brazil. Braz. J. Biol., v.62, p.191-196, 2002.

POPOFF, M.Y.; LE MINOR, L. Formules antigeniques des serovar de Salmonella. WHO Collaborating Centre for Reference and Research on Salmonella. France, Institut Pasteur, 1997.
PUMPUNI, C.B.; DEMAIO, J.; KENT, M. et al. Bacterial population Dynamics in three Anopheline species: the impact on Plasmodium sporogonic development. Am. J. Trop. Med. Hyg., v.54, p.214-218, 1996.

PUTMAN, R.J. Carrion and dung. The decomposition of animal wastes. London: Edward Arnold Ltd., 1983.

SHIMIZU, F.; HASHIMOTO, M.; TANIGUCHI, H. et al. Epidemiological studies on fly-borne epidemics. Report I. Significant role of flies in relation to intestinal disorders. J. Sanit. Zool., v.16, p.201-211, 1965.

TANADA Y.; KAYA, H.K.I. Insect pathology. New York: Academic, 1993. p.12-51. 